Step 2.

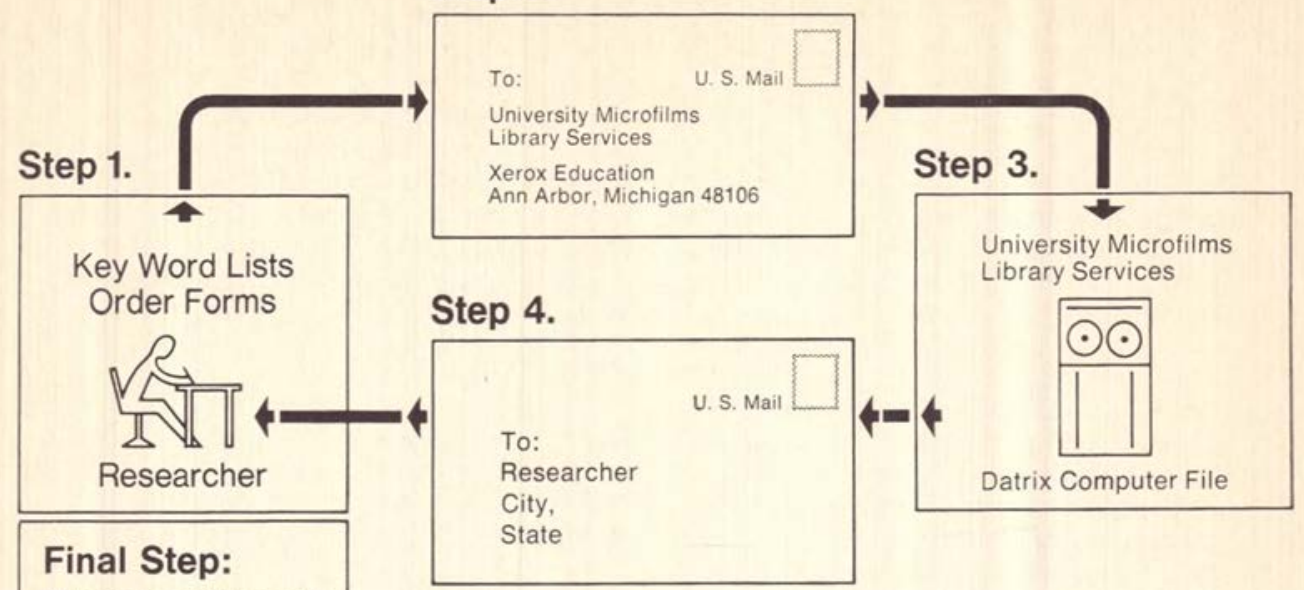

If desired, complete copies

\section{NEW COMPUTER SERVICE}

A new computer-based information retrieval system for locating doctoral dissertations for researchers is called DATRIX, for Direct Access To Reference Information. Its microfilm file contains some one hundred and twenty-six thousand doctoral dissertations from more than one hundred and ninety United States and Canadian universities, and some eighteen thousand new dissertations are added annually. The DATRIX system uses a key-word list that is actually a comprehensive computer vocabulary derived from the titles and subject classifications of doctoral dissertations.

By using one of three key-word lists, which are divided into major academic fields, the searcher formulates his own inquiry. The computer recognizes each selected key-word combination, or alternate, and makes its search, supplying the inquirer with a bibliography or list of doctoral dissertations pertinent to his query. He may then select titles of interest and order the complete dissertations from University Microfilms as a xerographic reproduction on paper or as positive $35 \mathrm{~mm}$ microfilm. The three key-word lists are: "Chemistry/Life Sciences," "Engineering/Physical Sciences," and "Humanities/Social Sciences."

For a $\$ 5$ charge the inquiry is processed by DATRIX, and the searcher receives a list of the first ten references produced by the computer. For the 11 th and succeeding references on his bibliography, the charge will be 10 cents for each reference.

The key-word list also shows an "occurrence number" indicating how many dissertations are represented by that key-word. By using this count for each of the key-words selected, a searcher will have a good estimate of how many references will turn up.

\section{FOR THE RUSSIAN BOOK SECTION}

\section{Reference and}

\section{Source Material}

- Russian Literature: Classics, Contemporary

- Linguistics and Literary Criticism

- English-Russian and Russian-English Dictionaries

- Russian Language Records

- Children's Literature

- Books on Art

- Books on Science

- Textbooks on mathematics, geography, natural sciences, history, etc.

- Socio-Economic Literature

- Russian Atlases and Maps

- Soviet Magazines and Newspapers

Inquire about our out-of-print books and back issue magazines.

Write for Catalogs \& Prices

Phone 212 CH 2-4500

FOUR GONTINENT BOOK GORP. DEPT. 727, 156 FIFTH AVENUE, NEW YORK, N. Y. 10010 